\title{
Benefit segmentation in the tourist accommodation market based on eWOM attribute ratings
}

\section{Karolina Nessel $^{1}$ (D) . Szczepan Kościółek ${ }^{1}$ (D) Ewa Wszendybył-Skulska ${ }^{1}$ (D) Sebastian Kopera ${ }^{1}$ (D)}

Received: 2 December 2019 / Revised: 24 March 2021 / Accepted: 27 March 2021 /

Published online: 19 April 2021

(c) The Author(s) 2021

\begin{abstract}
Given the increasing importance of electronic word-of-mouth (eWOM) in the global tourism market, the purpose of the study was to estimate weights customers assign to main attributes of tourist accommodations embodied in easily observed eWOM numerical ratings and subsequently to determine segments of customers with homogenous preferences. To this goal, the preferences tourists attach to price and seven other accommodation attributes rated by Internet users on Booking.com were revealed with the analytical hierarchy process (AHP). Next, a two-stage clustering procedure based on these preferences was undertaken followed by profiling of the clusters in terms of their socio-demographics and travel characteristics. The results show that even if the ranking of the attributes is roughly the same for all the segments (with cleanliness, value for money, and location always in top four), all eight attributes effectively segment tourists into three clusters: "quality-seekers" (45\% of the market), "bargain-seekers" (35\%), and "cleanliness-seekers" (20\%). The segments differ in terms of tourists' income and expenditures, type of accommodation, actual payer for accommodation, and trip purpose. In contrast, socio-demographics, and most tourists stay variables are alike across the segments. The proposed method of benefit segmentation provides a new perspective for an exploitation of eWOM data by accommodation providers in their marketing strategy.
\end{abstract}

Keywords Cluster analysis $\cdot$ Electronic word-of-mouth $\cdot$ Hospitality $\cdot$ Market segmentation $\cdot$ Booking.com

Karolina Nessel

karolina.nessel@uj.edu.pl

1 Institute of Entrepreneurship, Faculty of Management and Social Communication, Jagiellonian University in Kraków, ul. prof. S. Łojasiewicza 4, 30-348 Kraków, Poland 


\section{Introduction}

Heterogeneity of tourists calls for a segmentation of the market in order to achieve a better targeting, positioning, marketing, or revenue management (Dolnicar 2007; Ahani et al. 2019). In the case of tourist accommodation, the consumer segmentation is usually based on socio-demographic variables, psychographics, and travel-related criteria. However, the limits of this approach to segmentation (Crawford-Welch 1990) have led researches to shift focus on to product and service benefits sought by customers. Consequently, for some scholars (Bowen 1998; Kim et al. 2020), the benefit segmentation (grouping consumers desiring the same sets of benefits) offers the best understanding of consumer behaviour in different market segments.

In the contemporary hospitality market, consumers increasingly rely on online environment to evaluate the benefits of different accommodation options. In particular, electronic word-of-mouth (eWOM) has become one of the most important information sources for customers (Litvin et al. 2008; Filieri and McLeay 2013), and online textual reviews and ratings have been found to significantly influence tourists' choices of accommodation (Ye et al. 2009; Cantallops and Salvi 2014; Park et al. 2019; Hu and Yang 2020). Even if some researchers find that consumer textual reviews have a greater impact on consumer purchase behaviour than numerical ratings (Noone and McGuire 2013), others claim that, given the amount of online data, easy access and processing of the eWOM are critical and make consumer-generated numerical ratings more influential on product purchase decisions than more detailed information (Sparks and Browning 2011; Yang et al. 2018). Both numerical ratings and textual reviews are usually presented by most online travel agents (OTAs) or travel rating portals, such as Booking.com, Expedia.com, TripAdvisor.com, enabling accommodation providers to increase efficiency of their marketing strategies (Yacouel and Fleischer 2012; Yang et al. 2018; Xia et al. 2019). Nevertheless, to fully use these data for an effective pricing and competitive positioning strategies, revenue and marketing managers need to understand how consumers integrate price and multiple sources of non-prices information available on OTAs' websites in their multi-stage choice and booking process (Noone and McGuire 2013; Peng et al. 2018; Park et al. 2019; Hu and Yang 2020; Wang et al. 2020). The need gets even more urgent, as for many, especially medium and small accommodation providers, OTAs become the main distribution channel (Stangl et al. 2016). However, the smaller accommodation providers usually lack strong analytical capacities (Hyvärinen and Saltikoff 2010), and are not able to use advanced techniques developed on rich textual eWOM data. These organizations would profit from simpler models based on numerical eWOM indices.

The extant research on the role of both online textual reviews and numerical ratings in tourists' behaviour and its use in marketing strategies of accommodation providers is extensive (for a detailed literature review see, e.g., Rhee and Yang 2015a; Ahani et al. 2019). It has not, however, explored the use of numerical ratings on OTAs' websites as a base for the benefit segmentation, i.e., to 
group guests into homogenous clusters having the same preferences towards a set of accommodation attributes rated by OTA users. On the other hand, the research has shown that these preferences are heterogeneous among tourists grouped according to some a priori criteria: context of trip, residence of tourists, or type of traveller (Rhee and Yang 2015a; Wang et al. 2020).

Given the importance of numerical attribute ratings for guests' choice and booking behaviour and their potential use in marketing strategies built on benefit segmentation for accommodation providers (especially the smaller ones), as well as the research gap in this area, the objective of this study is threefold: (1) to estimate the relative salience of the desired benefits embodied in numerical OTA ratings of accommodation attributes for the customers; (2) to determine homogeneous customer segments based on the importance of these attributes; (3) to evaluate the size and other characteristics of the segments.

To this goal, the research undertakes a cluster analysis of guests according to the importance they attach to price and seven other attributes of a tourist accommodation rated by Internet users on Booking.com-i.e., cleanliness, comfort, facilities, staff, value for money, free $\mathrm{WiFi}$, location. Among ratings of accommodations made available by different online travel agents, those used by Booking.com are chosen because of Booking.com's clear dominance among travel websites worldwide (Ebizmba 2018) and online accommodation distribution channels in Cracow, the area of our research (Kościółek et al. 2018). Consequently, the findings of the study should be of practical interest mainly to the mangers of accommodations heavily dependent on Booking.com as their source of customers. From the theoretical perspective, the main contribution of this study is the adoption of attribute categories used by the dominating online travel agent as a cognitive structure for the benefit segmentation.

\section{Literature review}

\subsection{Benefit segmentation}

When the goal is to serve a heterogeneous market, dividing it into mutually exclusive and homogeneous groups has proven to be a useful and thus widely used idea among marketing managers. A condition for an effective market segmentation is the appropriate choice of breakdown variables. In an a priori segmentation, criteria are defined before the procedure (as they are well-known or come from a well-defined classification scheme). On the other hand, the segmentation post hoc is based on market research survey and is derived on variables that turn out the most efficient in determination of homogeneous groups (Green et al. 1977; Mazanec 2000). Usually, once the segmentation based on chosen variables is done, the defined groups are additionally profiled, i.e. described in terms of other variables of interests. This enables a better understanding of consumers' behaviour, but is also useful in segmentation validation (Brusco et al. 2017).

The procedure of segmentation is usually based on socio- and geo-demographics, psychographics, or behavioural variables (see e.g. Rondan-Cataluña and RosaDiaz 2014 for a literature review in the tourist accommodation market). However, 
according to Haley (1968), the way to effectively segment a market is to classify customers based on benefits they seek in a given product. The advantage of this approach for marketing and communication strategy formulation is grouping together customers with homogenous real needs, which are decisive in the purchase of the product (Loker and Perdue 1992; Kotler and Turner 1993; Frochot and Morrison 2001).

Unsurprisingly, benefit segmentation has been widely applied in the field of tourism, mainly to determine tourist segments according to their expected benefits of destinations, attractions, events, or activities (Paker and Vural 2016). Benefit studies in the accommodation market are relatively more limited (Guttentag et al. 2018). Usually, they are based on motives derived from interviews with customers and experts (Kim et al. 2020) or factor analysis of customers' surveys regarding multiple hotel selection criteria or satisfaction attributes and limited to a special subgroup of tourists: business travellers in luxury hotels (Chung et al. 2004), female travellers (Khoo-Lattimore and Prayag 2015), or Airbnb users (Guttentag et al. 2018). Also the study by Ahani et al. (2019) limits the investigation to the guests of spa hotels. However, the latter study is the only one using the attributes derived from the textual reviews authored by Internet users (on TripAdvisor's website) as the base for customers segmentation. The lack of a broader exploration of eWOM (other types of travellers and accommodations, other forms of eWOM) as the base for benefit segmentation in the accommodation market is puzzling considering the immense role of eWOM in this market.

\subsection{Electronic word-of-mouth}

Word-of-mouth is a complex process of information exchange between peers representing significant influencing power and, thus, shaping individual buying decisions and behaviours (Dichter 1966; Pan et al. 2007). The real revolution in WOM accompanied proliferation of the Internet, which offered individuals a new communication space, giving birth to eWOM (electronic Word-of-Mouth), defined as "all informal communications directed at consumers through Internet-based technology related to the usage or characteristics of particular goods and services, or their sellers" (Litvin et al. 2008). eWOM has been growing in importance since the early years of the twenty-first century (Bronner and De Hoog 2011), accompanied and fuelled by the rise of social media, which "flattened" the Internet and gave users new tools to create and publish their own content (O’Connor 2010; Filieri and McLeay 2013; King et al. 2014).

In the context of the customer decision-making process in tourism, eWOM is ranked the most important information source (Litvin et al. 2008; Filieri and McLeay 2013), and is probably the most important at the pre-trip stage, when tourists choose destination and most of the services they plan to buy during their trip. Extensive evidence search at this stage can be related to high risk involved in purchasing holiday product (Sirakaya and Woodside 2005). Information extracted from other travellers informs accommodation decisions (O'Connor 2010; Bronner and De Hoog 2011; Filieri and McLeay 2013), determines trust to particular suppliers 
and their offer (Sparks and Browning 2011; Dong et al. 2019), and shapes customer choices (Cantallops and Salvi 2014; Park et al. 2019; Hu and Yang 2020).

In the tourism industry, eWOM takes various forms supported by multitude of tools enabling creating content by users (Cheung and Thadani 2012), of which the most common are textual reviews and numerical ratings. The later provide a "shortcut" in a complex decision-making process (Sparks and Browning 2011) and reduce issues with interpreting a valence of text reviews (King et al. 2014; Yang et al. 2018). Moreover, the multi-dimensional numerical ratings of product attributes enable customers to verify the benefits that are the most relevant for them and provide consumers with a relatively fast and easy possibility to make a decision according to the ability of accommodation suppliers to perform on attributes of individual interest.

Notwithstanding these general observations, the latest research in hospitality eWOM has shown that the role of different online information elements (eWOM included) changes with the stage of booking process (Hu and Yang 2020) and consumers' distinctive online decision-making patterns (Park et al. 2019). The heterogeneity is also observable in the sets of accommodation attributes that the OTA users are the most sensible to. Actually, Rhee and Yang (2015a) have shown that these preferences are heterogeneous among TripAdvisor hotel guest grouped according to the context of their trip and their residence. In the same vein, Wang et al. (2020) have proved differences among different types of travellers in their approach to accommodation attributes derived simultaneously from TripAdvisor textual reviews and numeral ratings. Ahani et al. (2019), on the other hand, have found three homogenous clusters of spa hotel guests based on the relative salience of the attributes mentioned in the TripAdvisor textual reviews. This is unsurprising given a well-documented heterogeneity in relative importance of determinants of tourist accommodation selection or satisfaction.

\subsection{Determinants of tourist accommodation selection}

The research into the determinants of accommodation choice factors started with the seminal works by Lewis $(1984,1985)$, who tested 66 hotel attributes of which location and price turned out to be the most decisive ones. Since then, the number and details of the selection attributes identified by researchers have grown immensely (Chu and Choi 2000; Dolnicar and Otter 2003; Shah and Trupp 2020). Besides location and price, literature has shown, inter alia, the importance of room quality, service quality, cleanliness, safety and security, hotel reputation, or atmosphere (Kim et al. 2020). Moreover, these determinants have been proved to be heavily influenced by traveller type and trip purpose (Wang et al. 2020), gender (Hao and Har 2014; Kim et al. 2018), destination nature and origin of tourists (Ying et al. 2020). They have also been shown to be interlinked and dependent on the stage of accommodation selection (Hu and Yang 2020).

In this research, we follow Booking.com, which-as main numerical indices for each accommodation-presents its price and ratings of seven attributes: location, cleanliness, comfort, facilities, staff, value for money, and free WiFi quality. 
Price of an accommodation is habitually the basic decision criterion (Song et al. 2011), especially for leisure tourists (Lewis 1985; Chow et al. 1995; Parasuraman et al. 1998) For the business tourists price doesn't seem less important than for the leisure ones (Lewis 1985; Kim et al. 2020), but it is found to be of lesser significance than location, quality, and comfort (Wong and Chi-Yung 2002; Kim and Park 2017). Moreover, price is more important for those travelling less frequently and for shorter periods, as well as for those travelling with their families or friends (Wong and Chi-Yung 2002), deciding to stay at a lower standard hotel (Rhee and Yang 2015b), or for women than men (McCleary et al. 1994). On the other hand, the price discounts and promotions do not necessarily increase sales, as tourist may associate them negatively with a perceived hotel quality (Hu and Yang 2020).

Location encompasses accessibility of points of interests, transport convenience, and surrounding environment (Masiero et al. 2019). In particular, the location may be crucial for tourists who expect easy access to the places they want to visit and the events in which they intend to participate (Tsaur and Tzeng 1996). Similarly, business travellers prefer being located near a business meeting spot (McCleary et al. 1993). Although location has usually been perceived as the most important attribute of an accommodation (Barros 2005; Chou et al. 2008), there is a significant heterogeneity in tourists' hotel location preferences (Masiero et al. 2019). For instance, the location is of more importance than price, or value for money for women travelling on business (Hao and Har 2014), as well as for more affluent tourists (Zaman et al., 2016).

Cleanliness is one of the most important factors determining the choice of a particular hotel, and one of the main sources of eventual dissatisfaction with the stay (Lewis 1987; Mehta and Vera 1990; Saleh and Ryan 1992; Lin and Su 2003; Huang et al. 2015). Moreover, the concept of cleanliness has been shown to concern not only rooms, but also other hotel areas: bathrooms, toilets, hotel entrance, parking, lobbies, and restaurants. Cleanliness is also associated with safety (Kozak et al. 2007; Amblee 2015) and decreased health risks (Shin and Kang 2020). Some researchers have found that cleanliness is an attribute to which women pay more attention than men, both when choosing a hotel, and while staying at it (Zemke et al. 2015). It is also more important for business travellers than for leisure tourists (McCleary et al. 1993). On the other hand, Knutson (1988) has showed that cleanliness of the room is the most important attribute in choosing a hotel by tourists in the US, regardless of the type of tourists and accommodation.

Comfort at a hotel is usually seen through the prism of sleep quality, i.e. such factors as comfortable bed, quiet and soundproof rooms, appropriate temperature, lighting, room odour, and noise level (Liu et al. 2013; Rhee and Yang 2015b). Zaman et al. (2016) showed that comfort is less important when choosing a hotel than location or value for money. Nevertheless, its importance varies with type of the guest. According to Lockyer (2002), comfort is the most important attribute for business travellers and those travelling alone. By contrast, for those travelling with friends, comfort is the least important, whereas people travelling with families and as a couple value comfort lower than price, but higher than location and cleanliness.

Hotel facilities are usually associated with additional services (i.e. wet bar in the room, coffee machine or kettle in the room, safe box, luggage room, storage 
room for recreational equipment, free parking, etc.). Depending on the establishment and its standard, facilities are included in the price of stay, or paid additionally. Hotels, in order to be more competitive, try to offer their guests more and more facilities (Dolnicar and Otter 2003). However, the majority of studies prove that amenities are perceived as an attribute of lesser importance than price and location (Chu and Choi 2000), or value for money and staff (Qu et al. 2000). By contrast, for Chinese outbound travellers in Macau, room facilities proved to be the most important hotel choice factors (McCartney and Ge 2016). Facilities, although usually not the primary attribute of hotel choice, are more important for business tourists than for leisure ones (Chu and Choi 2000; Shanka and Taylor 2013).

Quality of personal interactions with staff is often a key element in the satisfaction with the quality of hotel services (Parasuraman et al. 1998; Kim et al. 2016), both for business and leisure travellers (Barsky and Labagh 1992), and particularly in higher end hotels (Chu and Choi 2000). However, other studies have found it of lesser importance than several other attributes (Rhee and Yang 2015a; Wang et al. 2020). Moreover, as an accommodation selection criterion the importance of this attribute is usually found to be relatively lower (Sohrabi et al. 2012; Wang et al. 2020).

Value for money is determined as a trade-off between perceived costs (mainly monetary ones) and benefits (Zeithaml 1988). While evaluating accommodation attributes customers search for the one presenting the highest value for the lowest possible price (Gupta and Kim 2010), regardless of the accommodation type (Hu and Hiemstra 1996). Value for money has been shown to be the most important factor of hotel choice by Parasuraman et al. (1998) and McCartney and Ge (2016), while Zaman et al. (2016) showed that value for money, following price, is the second important criterion.

Free and reliable WiFi at a hotel seems an indispensable component of the present-day hospitality offer. So far, however, research has pointed to the relatively small significance of this attribute for the hotel guests in their choice decisions (Lockyer 2005; Shanka and Taylor 2013), valuing it less than comfort and safety (Sohrabi et al. 2012). On the other hand, a weak WiFi is a frequent reason for a negative eWOM (Xu 2018).

Taken together, the studies reviewed thus far indicate that despite the extensive research on the heterogeneity of relative importance of different accommodation attributes for the tourist behaviour, the segmentation based on this heterogeneity is quite limited. Moreover, the benefit segmentation according to importance the customers attach to the attributes found in eWOM is restricted to the only study concerning spa hotel guests and based on textual reviews (Ahani et al. 2019). Therefore, the following section presents the results of the study undertaking the benefit segmentation in the accommodation market based on the set of attributes that are rated by Booking.com users.

The study was conducted within the framework of bounded rationality theory (Simon 1979) and multi-attribute utility theory (Keeney et al. 1993). The theories together stipulate that people act as rational as possible in the limits of their imperfect capacities of data analysis and base their decisions on a set of the most decisive 
criteria (with the use of heuristics and unequal weight accorded to readily accessible information).

\section{Materials and methods}

\subsection{Survey instrument}

The survey questionnaire consisted of two main sections fitted into two pages. The first included 28 pairwise comparisons of relative importance of seven crucial accommodation attributes adopted directly from the Booking.com review form (cleanliness, location, comfort, facilities, staff, value for money, and free WiFi), and an additional variable: price. In the second stage, 18 profiling questions were asked. All of them were derived from a review of the literature on benefit segmentation in tourism studies, and included socio-demographics (age, gender, country of residence, education level, occupation, monthly income), tourist stay characteristics (first time vs repeat visit to the destination, trip purpose, travel party composition, accommodation type and reservation channel, payer for the accommodation), and tourism consumption features (travel expenditure on accommodation, food and beverages, activities).

Initially, two versions of the survey were developed with different formulations of pairwise comparisons (numerical versus graphical scales)_Fig. 1 in Appendix. The pilot study carried out on 40 persons indicated that the graphical scale led to more consistent answers, and this version was adopted in the data collection process. The graphical answers were converted into numbers in the coding stage of the data preparation (rounding to the nearest integral value to match the numerical scale usually used in AHP). The final versions of the paper questionnaire were prepared in Polish and English.

\subsection{Data collection}

The target population of the study was tourists visiting Cracow, which is a UNESCO World Heritage site and a major tourist destination in Poland (over 14 million arrivals in 2019) famous for its cultural, historical, and architectural attractions. All tourists, regardless of their reservation channel in this particular trip, were targeted as they are all potential Booking.com customers.

The data were collected in the most popular tourist attractions of the city agglomeration between April and June 2018. As many tourists as possible were asked to complete the questionnaire. Each first available tourist met by an interviewer was asked to participate in the survey and approximately $20 \%$ of them agreed. Participants were first briefed by the interviewer about the purpose of the study and the way to indicate the relative importance in each pair of attributes. These explanations, accompanied by two examples, were also printed at the beginning of the survey sheet. 
As the most reliable data concerning tourist market in Cracow, based on accommodation suppliers' reports, indicate an average annual proportion of domestic to international tourists being 51:49 in 2016 (Statistical Office in Kraków 2017), a quota sampling was applied aiming to achieve a parity between both groups of visitors. The surveys were conducted in five waves-when the balance between domestic and international tourists was disturbed, interviewers targeted the under-represented group in the following wave. In total, 964 fully completed questionnaires were collected.

\subsection{Data analysis}

The data analysis in the study comprised three main stages. First, determination of relative weights customers attach to each criterion was performed using a part of an analytic hierarchy process. In AHP, which was introduced and developed by Saaty (1980), the relative weights result from the solution of Eigen value problem of the matrix made of all pairwise comparisons. In this research AHP Excel template developed by Goepel (2013) was used to solve the problem mathematically, and to determine the weighting and the consistence ratio of individual respondents.

The advantage of AHP in this study consists not only in its suitability in multicriteria decision-making problems, but also in its ability to handle situations of subjective judgements (Saaty 1980). On the other hand, its inconvenience lies in a certain difficulty for respondents in logical and consistent evaluation of all pairs of attributes. This difficulty rises with the number of attributes. The consistency ratio in AHP usually should not exceed 0.10 , but the threshold may be enlarged to 0.20 in more difficult situations (Saaty 2002). In our study, a consistency ratio not greater than 0.2 was observed in 540 surveys, i.e. $56 \%$ of the initial sample. Only these surveys made our final sample and were subsequently clustered and profiled.

In the second step of the data analysis, two-stage clustering procedure based on individual criteria weightings was applied in order to identify customer segments with similar preferences in terms of accommodation attribute weights. Firstly, Ward's hierarchical cluster analysis with the Euclidean distance was undertaken in order to determine the number of clusters. Secondly, a non-hierarchical K-means method was applied to define the final segments. According to the literature, a two-stage clustering procedure increases validity of solutions (Hair et al. 1998).

In the final stage of the data analysis, a profiling of the clusters in terms of their socio-demographics, and travel characteristics was carried out.

\section{Results}

\subsection{Sample profile}

The sample (Table 2) is roughly equally shared among males (49\%) and females (51\%), as well among international $(52 \%)$ vs. domestic (48\%) tourists. More than $3 / 4$ of the sample are comprised of people under 45 years old, employed or self-employed, with 
at least high school education. The majority of them (63\%) earn less than $1500 €$ per month. They are rather repeat visitors to Cracow (56\%), coming mainly for leisure (42\%), and mostly as individual tourists (88\%). They travel in an adult group (31\%) or in a couple (25\%), usually without children (90\%). Most of them stay fewer than five days in the city (82\%), usually in 3-star hotels (28\%) and private apartments (20\%), which they have booked personally via Booking.com (28\%), or someone else has booked for them (22\%). In any case, most (74\%) have paid for the accommodation themselves. The threshold of $40 €$ for daily expenses for accommodation concerns $63 \%$ of tourists, for food and beverages- $62 \%$ of them, and for tourist activities-almost all of them (88\%).

\subsection{Pairwise comparisons of attributes}

The relative importance of accommodation attributes was determined by pairwise comparisons. For the total sample, the most important criterion is cleanliness (0.189), closely followed by value for money $(0.171)$, location $(0.149)$, and price $(0.142)$. The weight of comfort itself is at average level (0.113), while facilities (0.084), free WiFi (0.081) and staff (0.072) are valued the least-Table 1.

A visual inspection of data and the results of Lilliefors tests indicate that criteria variables are not normally distributed. Therefore, in subsequent analysis involving these variables, non-parametrical tests are used. Regarding the correlation between the criteria, no multicollinearity is observed, and, thus, a clustering procedure based on these variables is possible.

\subsection{Cluster analysis}

The segmentation analysis based on eight accommodation criteria allows to determine three clusters of tourists (Table 1). The biggest segment in the market (45\%), Cluster 1 (labelled "quality-seekers") groups tourists relatively more sensitive to such criteria as comfort, facilities, free $\mathrm{WiFi}$, and staff. These variables make $47 \%$ of weight for the tourists of this cluster, at the relative expense of a lower than average importance attached to price $(10 \%)$.

The second in terms of size (35\%) is Cluster 2 ("bargain-seekers"), in which price is the most important criterion (23\%). Interestingly, compared to quality-seekers, these tourists also relatively more value accommodation location. At the same time, they put lower weight on comfort, facilities, free WiFi, and staff, but they attach the same importance to cleanliness, and value for money.

The smallest, Cluster 3 (20\%, "cleanliness-seekers"), comprises tourists giving an extra importance to cleanliness (31\%), at the relative expense of value for money.

To determine the influence of each variable on creation of the clusters, a series of Kruskal-Wallis tests was performed. Results (Table 1) indicate that, although all variables have statistically significant impact $(\mathrm{p}<0.01)$, the strength of the impact is not similar. In fact, the clusters differ mostly in terms of importance attached to price and cleanliness, while the differences are the smallest in case of the weights of value for money and location. In regard to within-cluster variability, the standard 
Table 1 Cluster analysis-means, standard deviations, and Kruskal-Wallis tests

\begin{tabular}{lllllr}
\hline & Total & $\begin{array}{l}\text { Cluster 1: } \\
\text { quality-seekers } \\
(n=242)\end{array}$ & $\begin{array}{l}\text { Cluster 2: } \\
\text { bargain-seek- } \\
\text { ers }(n=187)\end{array}$ & $\begin{array}{l}\text { Cluster 3: clean- } \\
\text { liness-seekers } \\
(n=111)\end{array}$ & $H$ \\
\hline Cleanliness & $0.189(0.086)$ & $0.156^{\mathrm{a}}(0.050)$ & $0.153^{\mathrm{a}}(0.051)$ & $0.310(0.069)$ & $243.74 * * *$ \\
Value for money & $0.171(0.088)$ & $0.177^{\mathrm{a}}(0.090)$ & $0.178^{\mathrm{a}}(0.088)$ & $0.146(0.074)$ & $9.75^{* *}$ \\
Location & $0.149(0.070)$ & $0.136^{\mathrm{a}}(0.059)$ & $0.173(0.081)$ & $0.138^{\mathrm{a}}(0.062)$ & $22.80^{* * *}$ \\
Price & $0.142(0.088)$ & $0.097^{\mathrm{a}}(0.050)$ & $0.226(0.079)$ & $0.096^{\mathrm{a}}(0.056)$ & $254.45^{* * *}$ \\
Comfort & $0.113(0.048)$ & $0.132(0.044)$ & $0.088(0.033)$ & $0.114(0.054)$ & $107.84^{* * *}$ \\
Facilities & $0.084(0.040)$ & $0.105(0.040)$ & $0.065^{\mathrm{a}}(0.031)$ & $0.069^{\mathrm{a}}(0.030)$ & $141.65^{* * *}$ \\
Free WiFi & $0.081(0.072)$ & $0.103(0.082)$ & $0.065^{\mathrm{a}}(0.062)$ & $0.060^{\mathrm{a}}(0.050)$ & $64.32^{* * *}$ \\
Staff & $0.072(0.039)$ & $0.093(0.042)$ & $0.052^{\mathrm{a}}(0.023)$ & $0.058^{\mathrm{a}}(0.032)$ & $139.55^{* * *}$ \\
\hline
\end{tabular}

For each variable (row), the medians for different customer segments with the same superscript (a) are not significantly different based on Dunn's post hoc tests

$* p<0.05 ; * * p<0.01 ; * * * p<0.001$

deviations (Table 1) indicate that the clusters are most homogenous in terms of cleanliness, and the least in terms of free WiFi.

\subsection{Profile analysis}

In order to profile the segments, cross tabulations with socio-economic and demographic variables, tourist stay characteristics, and consumption variables were undertaken (Table 2). The chi-square tests indicate that clusters are similar in terms of socio-demographics (gender, age, education, country of residence, occupation), and most tourist stay variables (first vs. repeat visit, travel party composition, presence of children, length of stay, accommodation reservation channel). The differences lie mainly in economic dimensions: tourists' income and expenditures, as well as type of accommodation, actual payer for the accommodation, and, additionally, trip purpose.

With regard to income variable, among people earning less than $1500 €$ per month, there is a clear overrepresentation of bargain-seekers tourists, and a smaller underrepresentation of quality-seekers (in 1000-1499€ group). The situation is symmetrical among higher income tourists: a clear underrepresentation of bargain-seekers, and an overrepresentation of quality-seekers (especially in 1500-1999€ group). On the other hand, the distribution of cleanliness-oriented tourists follows the average distribution in the market.

The pattern of heterogeneity is roughly the same in case of spending on accommodation: the spenders of less than $20 €$ per night are relatively more present in the price sensitive cluster, and less among quality and cleanliness-seekers, while prices of more than $40 €$ are paid relatively less often by price sensitive customers. The situation is similar in regard to spending on tourist accommodation: small spenders (1-19€) are overrepresented in Cluster 2, and underrepresented in Cluster 1. Additionally, the latter cluster has an overrepresentation of 


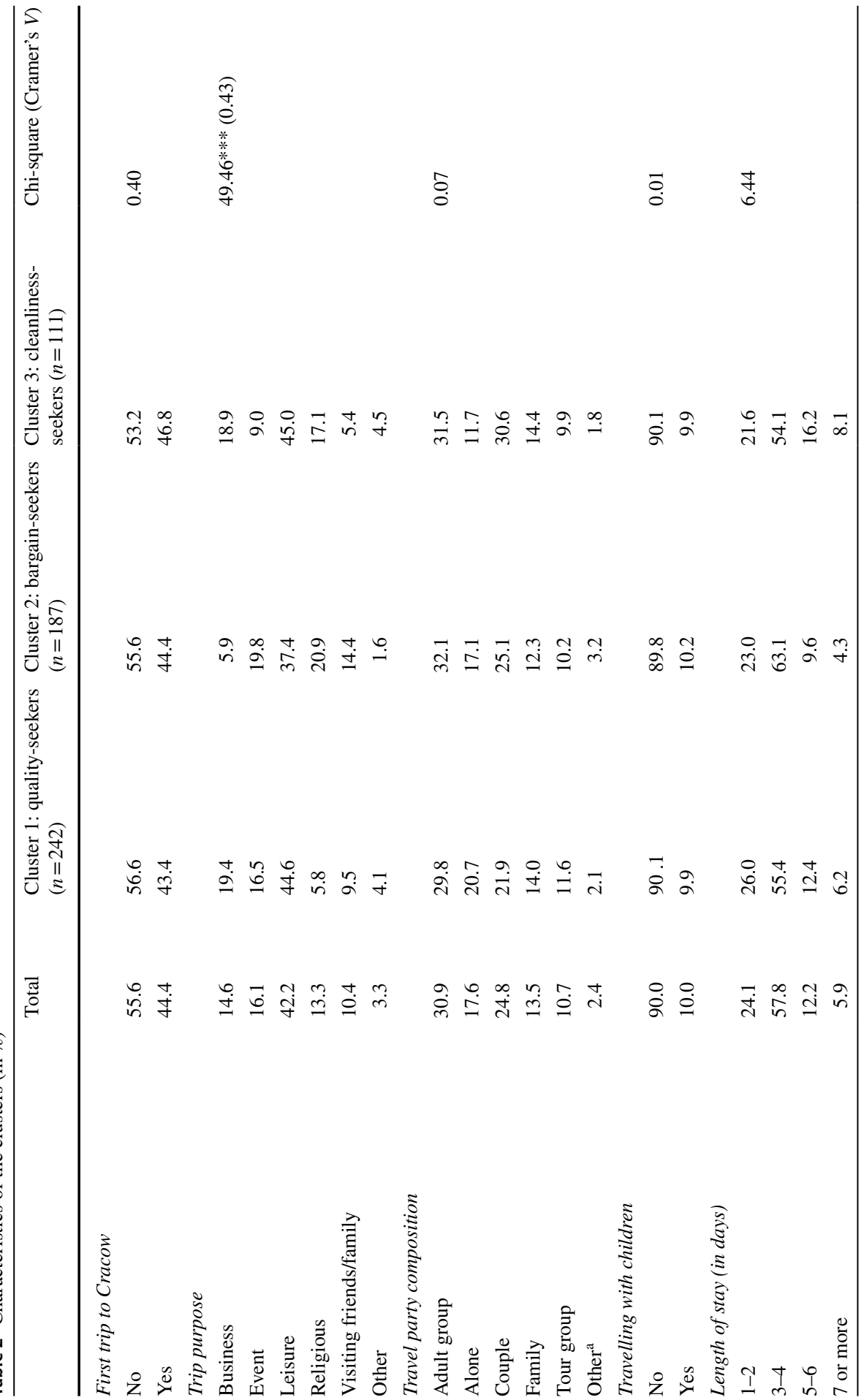




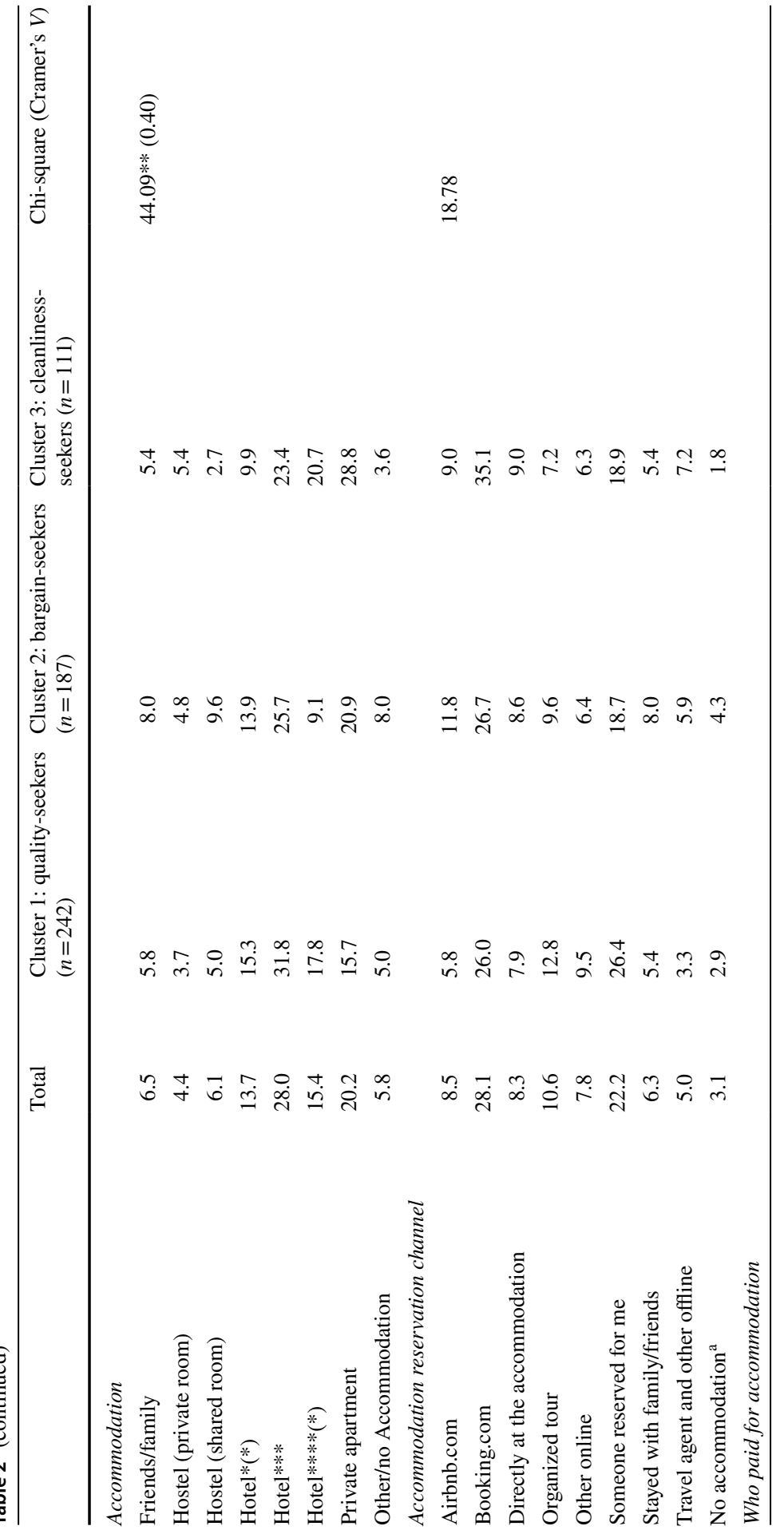




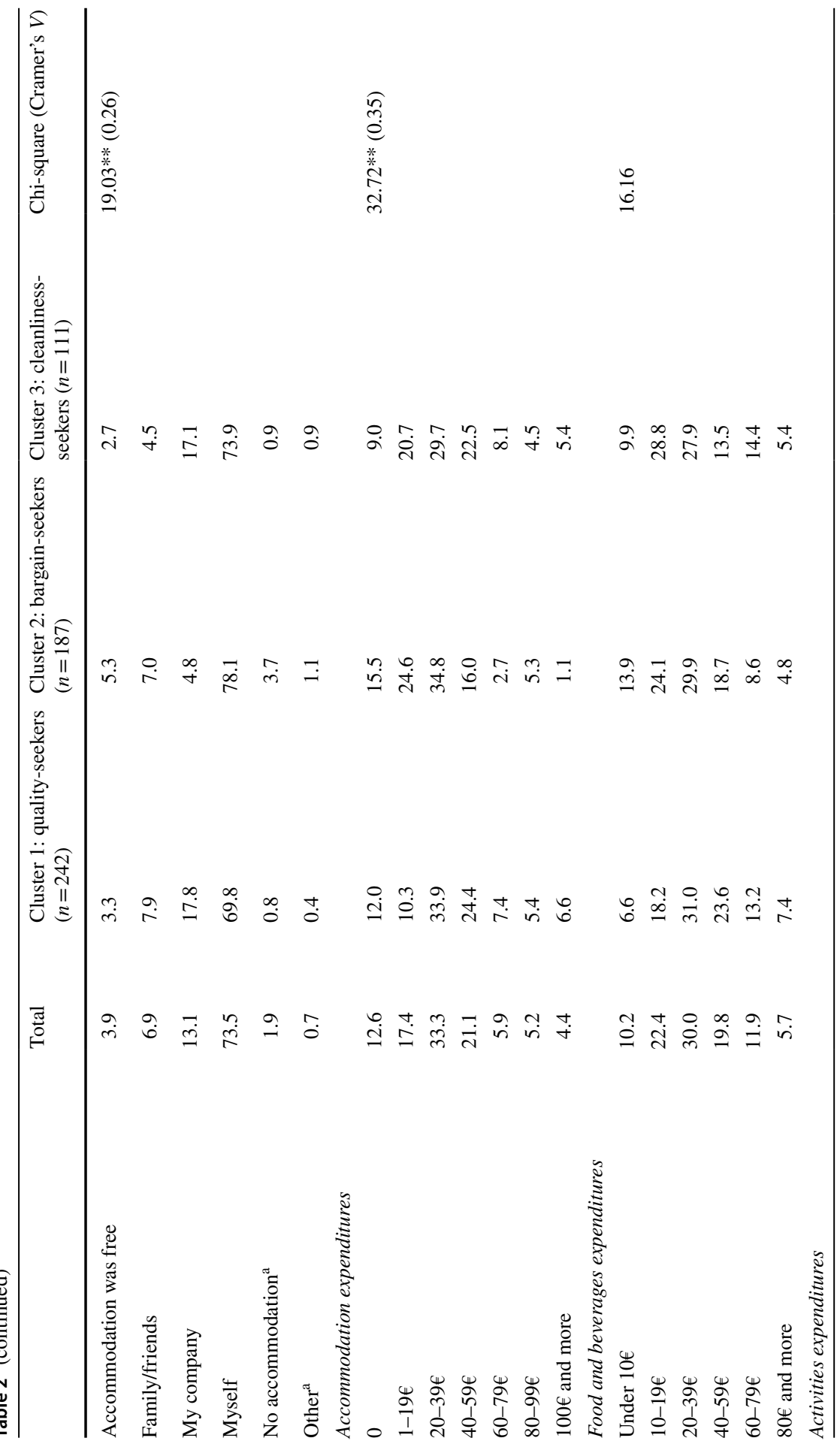




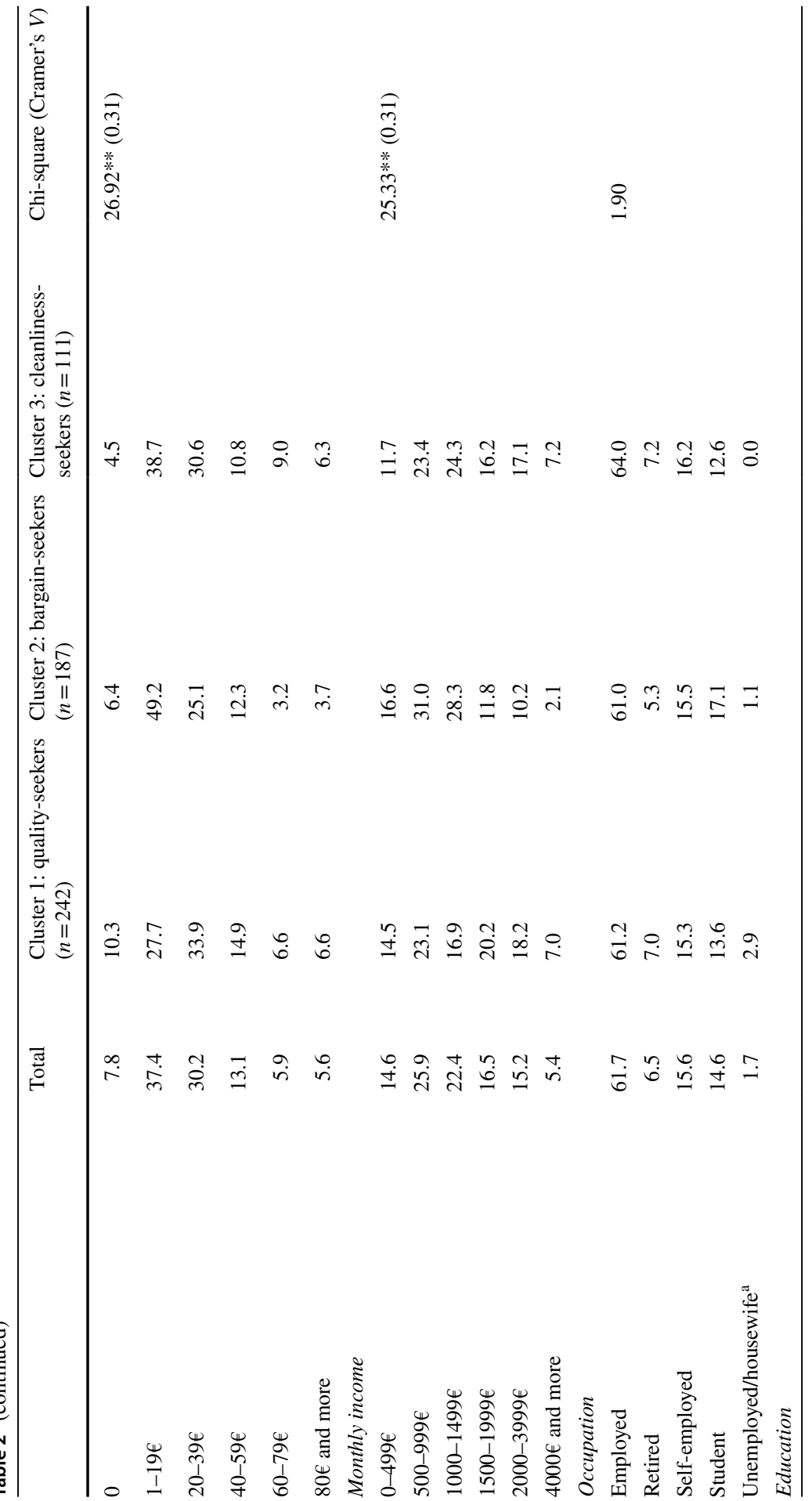


280

K. Nessel et al.

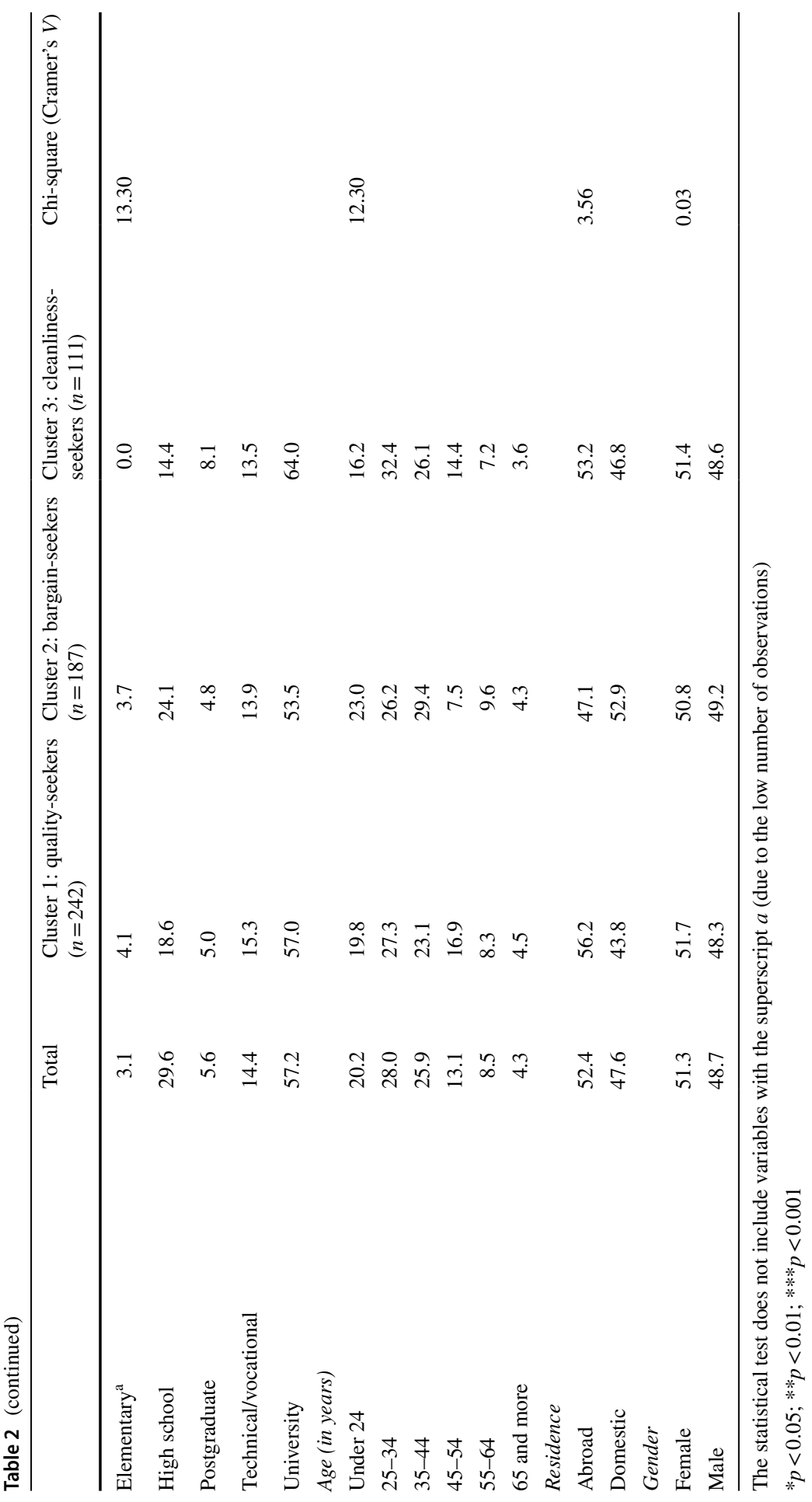

Springer 
tourists spending 40-59€. There is no specificity in terms of activity spending for Cluster 3. Finally, although the association of the clusters and spending on food and beverages is statistically significant only at $\mathrm{p}<0.10$, logical relations can be observed in this regard: higher spenders are found relatively more often among comfort-oriented tourists, while smaller spenders are prevailing among price (and to a lesser degree also cleanliness)-sensitive guests. According to Cramer's tests, the associations between clusters on the one hand, and income and spending variables on the other, are strong (with the exception of spending on food and beverages).

An even stronger association is observed between cluster and accommodation type. In fact, hostel shared rooms are relatively more often chosen by price conscious tourists, 1 or 2-star hotel guests are underrepresented in the cleanliness-seeking cluster, while 3-star hotel customers are overrepresented in the quality-seeking cluster. Unsurprisingly, 4 and 5-star hotels are relatively less often chosen by priceoriented tourists, and relatively more often by cleanliness sensitive ones. Finally, private apartments are clearly relatively less chosen by tourists focused on comfort, but relatively more often by guests looking for cleanliness.

The most important differences between clusters can be seen in terms of trip purpose (an exceptionally high association, $\mathrm{V}_{\text {ACCOMODATION }}=0.43$ ). In fact, among tourists coming to Cracow for religious purposes, there were relatively fewer comfort-oriented, but more price-oriented people. On the other hand, people coming to see relatives and friends were underrepresented in the cleanliness-oriented cluster, but overrepresented in the price sensitive cluster. Moreover, price-oriented people were underrepresented among tourists coming for business and leisure. Finally, in the event category, there were relatively fewer cleanliness-sensitive persons.

The final variable differentiating the clusters is the actual payer for the accommodation (the strength of this association is moderately strong). The most striking, and expected, relative difference is observed when the accommodation is paid by the tourist's company-in this case, there is a clear underrepresentation of bargain-seeking guests.

Overall, the data analysis leads to the determination of three distinctive clusters:

- Cluster $1-$ quality-seekers (45\% of the sample). The tourists in this cluster stand out because of the higher weights they put on accommodation quality embodied by comfort, facilities, free $\mathrm{WiFi}$, and staff. And they are ready to pay a higher price for it. They look for the accommodation quality choosing (relatively more often than the rest of the market) 3-star hotels, and avoiding private apartments. They also spend more than others on tourist attractions, and food and beverages. Their higher spending is matched by their higher income. They are relatively underrepresented among religious tourists in Cracow.

- Cluster 2-bargain-seekers (35\% of the sample). The most striking feature of this cluster is the high importance attached to the price criterion. Moreover, the tourists in this cluster value localization slightly more, and comfort slightly less than the others. Consequently, their spending on accommodation, and also on other tourist attractions, as well as food and beverages, is lower, as they tend to stay with friends, family, or in hostel shared rooms relatively more often. Therefore, they are under- 
represented among 4 and 5-star hotel guests. Their consumption pattern is correlated with their lower than average personal income. The purpose of their visit to Cracow was less business and leisure-oriented, as they came more to see friends and relatives, and for religious reasons.

- Cluster 3-cleanliness-seekers (20\% of the sample). The tourists in this cluster are extremely sensitive to cleanliness criterion and are ready to give up on value for money. Effectively, compared to other clusters, they are relatively unlikely to pay less than $40 €$ per night or choose a free accommodation. In fact, they are overrepresented in 4 and 5-star hotels, and among private apartment customers (and underrepresented in budget accommodations). Their trip purpose to Cracow was relatively rarely an event or visiting family and friends.

Notwithstanding the above differences among the clusters, some similarities across all three groups have to be underscored: (1) cleanliness, value for money, and location are among top priorities among tourists in all segments, making ca. 50\% of total criteria weights; (2) all segments are most similar in terms of high importance attached to value for money, and location criteria; (3) clusters are alike in terms of socio-demographics, and most tourist stay variables.

\section{Discussion and conclusion}

\subsection{Discussion}

Driven by the importance of eWOM attribute ratings for guests' choice and booking behaviour and its potential use in marketing strategies for accommodation providers, this study determined the relative importance tourists attach to the set of accommodation attributes embodied in numerical ratings on the website of the dominant online travel agent, Booking.com, and defined segments of tourists sharing the same combinations of desired attributes.

In the limited literature on benefit segmentation in the accommodation sector, various approaches to enumerating benefits have been applied for consumer segmentation-interviews with customers and experts (Kim et al. 2020), factor analysis of customers' surveys based on literature review (Chung et al. 2004; Guttentag et al. 2018), or data mining of textual eWOM (Ahani et al. 2019). In this study, in contrast, a predetermined set of attribute ratings present on the online travel agent's website has been adopted as potential clients are assumed to base their decisions on a limited set of the most readily accessible information (Simon 1979; Keeney et al. 1993).

Naturally, the more granular benefit classification is, the more precise results in terms of customers' needs may be (potentially) obtained. For example, Chung et al. (2004) enlisted 16 benefit factors to segment customers. However, the rise of the number of benefits enlisted decreases the tool's practicality for day-to-day 
managerial application. This study shows that the seven benefits listed on Booking.com together with price, all of which (except one: free $\mathrm{WiFi}$ ) appeared in the previously cited work of Chung et al. (2004), are sufficient to identify basic customer segments with distinct travel consumption behaviours.

Actually, all eight attributes discriminate tourists, even if their ranking is roughly the same for the delimited clusters. Among the four top criteria for most of the visitors one finds cleanliness, value for money, and location, confirming findings by many scholars having used other sets of attributes (Parasuraman et al. 1998; Zaman et al. 2016; McCartney and Ge 2016; Ahani et al. 2017; Wang et al. 2020). Also the findings of Rhee and Yang (2015a), has been partially confirmed, with the exception of localisation that turned out clearly less important in their study than sleep quality, room, and service. On the other hand, facilities, free $\mathrm{WiFi}$, and staff are generally valued the least-as also observed by Chu and Choi (2000), Qu et al. (2000) and Shanka and Taylor (2013).

Notwithstanding general similarities in the attribute rankings, differences in weights accorded to each attribute justify grouping tourists in three clusters. The tourists referred to as "quality-seekers" (Cluster 1) are probably the most attractive for the accommodation industry, mainly for hotels. They are the most profitable customers for hotel establishments because of their ability to pay more for a stay, provided the comfort of the services offered is higher, and the scope of amenities is greater. The attributes valued relatively more in this cluster match those found among tourists spending more on accommodation in Paris or Macao (Zaman et al. 2016; McCartney and Ge 2016).

Cluster 2 represents "bargain-seekers", i.e. tourists looking for accommodation facilities offering low prices, but, at the same time, conveniently located. According to Lewis (1985), price and location are the basis for the hotel selection mainly for leisure tourists. In our research sample, the frugal tourists come to Cracow mostly for leisure, but, at the same time, they were relatively overrepresented among tourists coming for an event, religious purpose, and to see friends and relatives. The latter relationship is consistent with observations by Wong and Chi-Yung (2002). The frugal tourists in Cracow show lower incomes, which, in turn, makes them choose accommodation of lower standards, confirming the findings by $\mathrm{Chu}$ and Choi (2000), who showed that, for such tourists, comfort and facilities are less important than location and price.

"Cleanliness-seekers" in Cluster 3 may be considered demanding, yet profitable clients. For them, the focal attribute is cleanliness, and they are ready to pay the price for it. They are wealthy tourists overrepresented among customers of 4 and 5-star hotels, and private luxury apartments. These characteristics confirm findings by Rhee and Yang (2015b) who proved that hotel guests using high standard hotels consider cleanliness to be the most important attribute. Moreover, in our study, the cleanliness is high on most of the tourists' priorities lists when choosing an accommodation, corroborating findings of many researchers studying either hotel choice criteria or sources of hotel dissatisfaction (Lockyer 2003; Zaman et al. 2016). 


\subsection{Implications and contributions}

The study offers some theoretical, managerial, as well as methodological implications. From the theoretical point of view, the study contributes to the literature on travellers' behavioural preferences in the accommodation market. Actually, the majority of research in this area explore the heterogeneity of customers' behaviour based on the travellers' type or trip purpose/context-i.e. segmenting tourists into business versus non-business group, with the latter group being often divided into solo, family, couples, friends, etc. (e.g., Kim and Park 2017; Rhee and Yang 2015a; Wang et al. 2020). In this study, in contrast, the primary grouping is made on the basis of preferences towards the set of attributes and only later the segments are profiled according to the trip purpose and travel party composition. The results show that there is no difference between clusters of "quality seekers" and "cleanliness seekers" in terms of representation of business and non-business travellers as there is no difference across all three clusters in terms of travel party composition. The result supports, therefore, the need to study the heterogeneity of attribute importance independently of these contexts (as in this study) or within these contexts (as done by Kim et al. 2020).

In fact, this study shows that the segmentation based on Booking.com attributes doesn't align with differences in most of the travel and demographic variables. In contrast, it does correlate with main tourist consumption variables (like expenditure on accommodation and activities, type of accommodation). These results further support the conclusions by Bowen (1998), that benefits sought are more universal predicates of customer behaviour than demographics or travel related features.

Obviously, attributes like quality, price, or cleanliness have a grounded position in accommodation sector literature, but mostly as attributes of hotel service quality post hoc (Tsaur and Tzeng 1996; Chu and Choi 2000; Albayrak and Caber 2015; Rhee and Yang 2015a; Wang et al. 2020), and criteria of hotel choice (e.g., Wilensky and Buttle 1988; Dolnicar and Otter 2003); rarely, however, as the base for benefit segmentation (Ahani et al. 2019; Kim et al. 2020). To the authors' best knowledge, this research was the first of this scope adopting attribute ratings used by the dominating OTA as a cognitive structure for benefit segmentation.

From the managerial point of view, the proposed method of benefit segmentation provides a new perspective of an easy exploitation of eWOM data for accommodation providers. In fact, a comparison of an actual price and evaluation of the accommodation by customers in regard to the seven Booking.com review attributes, on the one hand, with the benefits sought by the target segments (chosen among the three identified in this study) on the other, may help determine necessary adjustments in the providers' marketing strategy. In addition, the combination of attributes of the biggest importance for the target segment and highly rated by users may become the selling point in the communication of the enterprise. Likewise, it may serve to 
assess the relative market position compared to the direct competitors (also listed by Booking.com) and to allocate the limited resources to the critical attributes. These simple techniques seem of particular interest for smaller suppliers, which often lack capacities to fully explore the potential of eWOM data (e.g., to run the advanced data mining analysis based on eWOM textual comments as proposed by Xia et al., 2019) and give ground not only to chain hotels, but also to OTAs (Toh et al. 2011).

From a methodological point of view, we replaced the factor analysis, which is mostly used to produce variables for a subsequent cluster analysis (Tkaczynski et al. 2010) with pair-wise comparisons derived from the AHP procedure. This method seems to be more accurate when the criteria are already present in the OTA review forms, and potential customers simply determine their own priorities based on a published list of ratings. However, like other authors (e.g., Lee and Ross 2012; Singh 2016), who applied AHP in the evaluation of individual customers' criteria, we also encountered the problem of a large number of inconsistent answers (44\%). Lee and Ross (2012) suggested that researchers could try to resolve the issue reducing the number of factors and giving detailed instructions about AHP logic. The adoption of the best-worst multi-criteria decision-making method, the newer form of pair-wise comparison proposed by Rezaei (2015), could also be considered for this kind of research project. This tool, however, requires an electronic form of surveying.

\subsection{Limitations and future research}

Limitations of our research include the quota sampling (limiting representativeness of the results), and the declarative character of relative importance indications by tourists. Furthermore, it would be worth investigating how customers use online ratings from sites like Booking.com, particularly how often they go down to elementary ratings and not remain on the aggregated rating level. We cannot also say whether presented segmentation is destination-dependent or influenced by travellers' country/culture of origin. Future research, therefore, could verify our findings in other geographical and cultural contexts.

\section{Appendix}

See Fig. 1. 


\begin{tabular}{|c|c|c|c|c|c|c|c|c|c|c|c|c|c|c|c|c|c|c|c|c|}
\hline & & 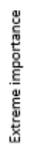 & 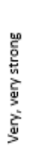 & 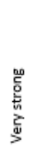 & 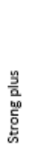 & $\begin{array}{l}\text { no } \\
\text { ఏ్ } \\
\text { s. }\end{array}$ & $\begin{array}{l}\frac{\mathrm{a}}{\mathrm{a}} \\
\frac{\mathrm{g}}{\mathrm{v}} \\
\frac{\mathrm{v}}{\mathrm{y}} \\
\frac{\mathrm{o}}{2}\end{array}$ & $\begin{array}{l}\text { पूँ } \\
\frac{\mathrm{g}}{2} \\
\frac{0}{z}\end{array}$ & $\begin{array}{l}\text { 尊 } \\
3\end{array}$ & 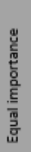 & $\begin{array}{l}\text { 盖 } \\
3\end{array}$ & 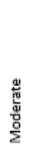 & 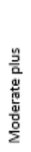 & 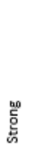 & 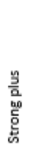 & 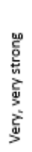 & 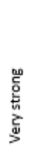 & 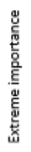 & & \\
\hline & Criterion A & 9 & 8 & 7 & 6 & 5 & 4 & 3 & 2 & 1 & 2 & 3 & 4 & 5 & 6 & 7 & 8 & 9 & Criterion B & \\
\hline 1 & Price & 9 & 8 & 7 & 6 & 5 & 4 & 3 & 2 & 1 & 2 & 3 & 4 & 5 & 6 & 7 & 8 & 9 & Location & 1 \\
\hline 2 & Price & 9 & 8 & 7 & 6 & 5 & 4 & 3 & 2 & 1 & 2 & 3 & 4 & 5 & 6 & 7 & 8 & 9 & Cleanliness & 2 \\
\hline 3 & Price & 9 & 8 & 7 & 6 & 5 & 4 & 3 & 2 & 1 & 2 & 3 & 4 & 5 & 6 & 7 & 8 & 9 & Comfort & 3 \\
\hline 4 & Price & 9 & 8 & 7 & 6 & 5 & 4 & 3 & 2 & 1 & 2 & 3 & 4 & 5 & 6 & 7 & 8 & 9 & Facilities & 4 \\
\hline 5 & Price & 9 & 8 & 7 & 6 & 5 & 4 & 3 & 2 & 1 & 2 & 3 & 4 & 5 & 6 & 7 & 8 & 9 & Staff & 5 \\
\hline 6 & Price & 9 & 8 & 7 & 6 & 5 & 4 & 3 & 2 & 1 & 2 & 3 & 4 & 5 & 6 & 7 & 8 & 9 & Value for money & 6 \\
\hline
\end{tabular}
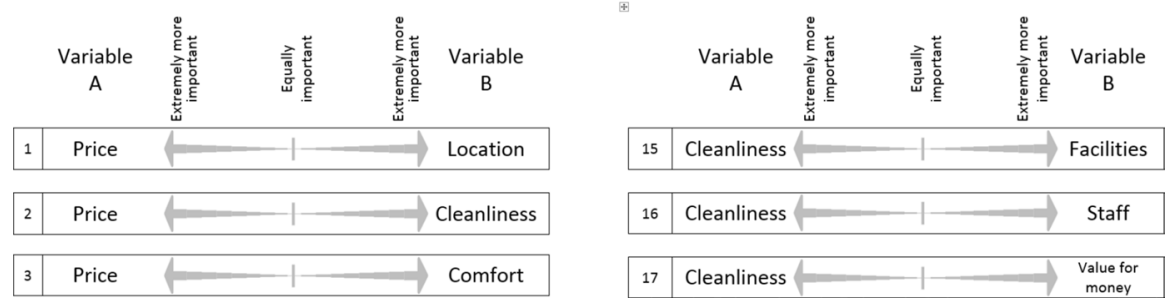

Fig. 1 Formulation of pairwise comparisons in the alternative pilot versions of the survey instrument

\section{Declaration}

Conflict of interest The authors declare that they have no conflict of interest.

Open Access This article is licensed under a Creative Commons Attribution 4.0 International License, which permits use, sharing, adaptation, distribution and reproduction in any medium or format, as long as you give appropriate credit to the original author(s) and the source, provide a link to the Creative Commons licence, and indicate if changes were made. The images or other third party material in this article are included in the article's Creative Commons licence, unless indicated otherwise in a credit line to the material. If material is not included in the article's Creative Commons licence and your intended use is not permitted by statutory regulation or exceeds the permitted use, you will need to obtain permission directly from the copyright holder. To view a copy of this licence, visit http://creativecommons.org/licen ses/by/4.0/.

\section{References}

Ahani A, Rahim NZA, Nilashi M (2017) Forecasting social CRM adoption in SMEs: a combined SEMneural network method. Comput Human Behav 75:560-578

Ahani A, Nilashi M, Ibrahim O et al (2019) Market segmentation and travel choice prediction in Spa hotels through TripAdvisor's online reviews. Int J Hosp Manag 80:52-77

Albayrak T, Caber M (2015) Prioritisation of the hotel attributes according to their influence on satisfaction: a comparison of two techniques. Tour Manag 46:43-50

Amblee N (2015) The impact of cleanliness on customer perceptions of security in hostels: a WOMbased approach. Int J Hosp Manag 49:37-39

Barros CP (2005) Measuring efficiency in the hotel sector. Ann Tour Res 32:456-477

Barsky JD, Labagh R (1992) A strategy for customer satisfaction. Cornell Hotel Restaur Admin Q $33: 32-40$

Bowen JT (1998) Market segmentation in hospitality research: no longer a sequential process. Int J Contemp Hosp Manag 10:289-296 
Bronner F, De Hoog R (2011) Vacationers and eWOM: who posts, and why, where, and what? J Travel Res 50:15-26

Brusco M, Singh R, Cradit D, Steinley D (2017) Cluster analysis in OM research: survey and recommendations. Int J Oper Prod Manag 37:300-320

Cantallops SA, Salvi F (2014) New consumer behavior: a review of research on eWOM and hotels. Int J Hosp Manag 36:41-51

Cheung CMK, Thadani DR (2012) The impact of electronic word-of-mouth communication: a literature analysis and integrative model. Decis Support Syst 54:461-470

Chou TY, Hsu CL, Chen MC (2008) A fuzzy multi-criteria decision model for international tourist hotels location selection. Int J Hosp Manag 27:293-301

Chu RKS, Choi T (2000) An importance-performance analysis of hotel selection factors in the Hong Kong hotel industry: a comparison of business and leisure travellers. Tour Manag 21:363-377

Chung KY, Oh SY, Kim SS, Han SY (2004) Three representative market segmentation methodologies for hotel guest room customers. Tour Manag 25:429-441

Chow KE, Garretson JA, Kurtz DL (1995) An exploratory study into the purchase decision process used by leisure travelers in hotel selection. J Hosp Leisure Mark 2(4):53-72

Crawford-Welch S (1990) Market segmentation in the hospitality industry. Hosp Res J 14:295-308

Dichter E (1966) How word-of-mouth advertising works. Harv Bus Rev 44:147-166

Dolnicar S (2007) Market segmentation in tourism. In: Woodside A, Martin D (eds) Tourism management: analysis, behaviour and strategy. CAB International, Cambridge, pp 129-150

Dolnicar S, Otter T (2003) Which hotel attributes matter? A review of previous and a framework for future research. In: Griffin T, Harris R (eds) Proceedings of the 9th annual conference of the Asia Pacific Tourism Association (APTA). University of Technology Sydney, pp 176-188

Dong B, Li M, Sivakumar K (2019) Online review characteristics and trust: a cross-country examination. Decis Sci 50:537-566

Ebizmba (2018) Top 15 most popular travel websites I May 2018. http://www.ebizmba.com/articles/ travel-websites. Accessed 31 Dec 2018

Filieri R, McLeay F (2013) E-WOM and accommodation: an analysis of the factors that influence travelers' adoption of information from online reviews. J Travel Res 53:44-57

Frochot I, Morrison AM (2001) Benefit segmentation: a review of its applications to travel and tourism research. J Travel Tour Mark 9:21-45

Goepel KD (2013) Implementing the analytic hierarchy process as a standard method for multi-criteria decision making in corporate enterprises - a new AHP excel template with multiple inputs. In: Proceedings of the international symposium on the analytic hierarchy process. Creative Decisions Foundation Kuala Lumpur, pp 1-10

Green PE, Carroll JD, Carmone FJ (1977) Design considerations in attitude measurement. In: Wind Y, Greenberg MG (eds) Moving ahead with attitude research. American Marketing Association, Chicago, pp 9-18

Gupta S, Kim HW (2010) Value-driven internet shopping: the mental accounting theory perspective. Psychol Mark 27:13-35

Guttentag D, Smith S, Potwarka L, Havitz M (2018) Why tourists choose airbnb: a motivation-based segmentation study. J Travel Res 57:342-359

Hair JF, Anderson RE, Tatham RL, Black WC (1998) Multivariate data analysis. Prentice-Hall, London

Haley R (1968) Segmentation: research tool. J Mark 32:30-35

Hao SJC, Har COS (2014) A study of preferences of business female travelers on the selection of accommodation. Procedia Soc Behav Sci 144:176-186

Hu C, Hiemstra SJ (1996) Hybrid conjoint analysis as a research technique to measure meeting planners' preferences in hotel selection. J Travel Res 35:62-69

Hu X, Yang Y (2020) Determinants of consumers' choices in hotel online searches: a comparison of consideration and booking stages. Int J Hosp Manag 86:102370

Huang H, Lunhua Mao L, Wang J, Zhang JJ (2015) Assessing the relationships between image congruence, tourist satisfaction and intention to revisit in marathon tourism: the Shanghai International Marathon. Int J Sport Mark Spons 16:46-66

Hyvärinen O, Saltikoff E (2010) Social media as a source of meteorological observations. Mon Weather Rev 138:3175-3184

Keeney RL, Raiffa H, Meyer RF (1993) Decisions with multiple objectives: preferences and value tradeoffs. Cambridge University Press 
Khoo-Lattimore C, Prayag G (2015) The girlfriend getaway market: segmenting accommodation and service preferences. Int J Hosp Manag 45:99-108

Kim D, Park BJ (2017) The moderating role of context in the effects of choice attributes on hotel choice: a discrete choice experiment. Tour Manag 63:439-451

Kim B, Kim S, Heo CY (2016) Analysis of satisfiers and dissatisfiers in online hotel reviews on social media. Int J Contemp Hosp Manag 28:1915-1936

Kim J, Kim PB, Kim J (2018) Impacts of temporal and gender difference on hotel selection process. J Hosp Mark Manag 27:711-732

Kim D, Hong S, Park BJ, Kim I (2020) Understanding heterogeneous preferences of hotel choice attributes: do customer segments matter? J Hosp Tour Manag 45:330-337

King RA, Racherla P, Bush VD (2014) What we know and don't know about online word-of-mouth: a review and synthesis of the literature. J Interact Mark 28:167-183

Knutson BJ (1988) Frequent travelers: making them happy and bringing them back. Cornell Hotel Restaur Adm Q 29:82-87

Kościółek S, Nessel K, Wszendybył-Skulska E, Kopera S (2018) Who are the tourists booking their accommodations online? A segmentation study of the Cracow market. Barom Reg 16:91-100

Kotler P, Turner RE (1993) Marketing management: analysis, planning, and control. Prentice-Hall Englewood Cliffs

Kozak M, Crotts JC, Law R (2007) The impact of the perception of risk on international travellers. Int J Tour Res 9:233-242

Lee S, Ross SD (2012) Sport sponsorship decision making in a global market: an approach of analytic hierarchy process (AHP). Sport Bus Manag An Int J 2:156-168

Lewis RC (1984) The basis off hotel selection. Cornell Hotel Restaur Admin Q 25:54-69

Lewis RC (1985) Predicting hotel choice: the factors underlying perception. Cornell Hotel Restaur Admin Q 25:82-96

Lewis RC (1987) The measurement of gaps in the quality of hotel services. Int J Hosp Manag 6:83-88

Lin Y, Su HY (2003) Strategic analysis of customer relationship management - a field study on hotel enterprises. In: Total quality management and business excellence. Taylor \& Francis, pp 715-731

Litvin SW, Goldsmith RE, Pan B (2008) Electronic word-of-mouth in hospitality and tourism management. Tour Manag 29:458-468

Liu S, Law R, Rong J et al (2013) Analyzing changes in hotel customers' expectations by trip mode. Int J Hosp Manag 34:359-371

Lockyer T (2002) Business guests' accommodation selection: the view from both sides. Int J Contemp Hosp Manag 14:294-300

Lockyer T (2003) Hotel cleanliness-how do guests view it? Let us get specific. A New Zealand study. Int J Hosp Manag 22:297-305

Lockyer T (2005) The perceived importance of price as one hotel selection dimension. Tour Manag 26:529-537

Loker LE, Perdue RR (1992) A benefit-based segmentation of a nonresident summer travel market. J Travel Res 31:30-35

Masiero L, Yang Y, Qiu RTR (2019) Understanding hotel location preference of customers: comparing random utility and random regret decision rules. Tour Manag 73:83-93

Mazanec JA (2000) Market segmentation. In: Jafari J (ed) Encyclopedia of tourism. Routledge, London, pp 374-375

McCartney G, Ge Z (2016) An examination of the pull and push factors influencing hotel selection by Chinese outbound travelers. Int J Tour Sci 16:41-59

McCleary KW, Weaver PA, Hutchinson JC (1993) Hotel selection factors as they relate to business travel situations. J Travel Res 32:42-48

McCleary KW, Weaver PA, Lan L (1994) Gender-based differences in business travelers' lodging preferences. Cornell Hotel Restaur Admin Q 35:51-58

Mehta SC, Vera A (1990) Segmentation in Singapore. Cornell Hotel Restaur Admin Q 31:80-87

Noone BM, McGuire KA (2013) Pricing in a social world: the influence of non-price information on hotel choice. J Revenue Pricing Manag 12:385-401

O'Connor P (2010) Managing a Hotel's Image on TripAdvisor. J Hosp Mark Manag 19:754-772

Paker N, Vural CA (2016) Customer segmentation for marinas: evaluating marinas as destinations. Tour Manag 56:156-171

Pan B, MacLaurin T, Crotts JC (2007) Travel blogs and the implications for destination marketing. J Travel Res 46:35-45 
Parasuraman A, Zeithaml VA, Berry L (1998) SERVQUAL: a multiple-item scale for measuring consumer perceptions of service quality. J Retail 64:12-37

Park S, Yin Y, Son BG (2019) Understanding of online hotel booking process: a multiple method approach. J Vacat Mark 25:334-348

Peng HG, Zhang HY, Wang JQ (2018) Cloud decision support model for selecting hotels on TripAdvisor. com with probabilistic linguistic information. Int J Hosp Manag 68:124-138

Qu H, Ryan B, Chu R (2000) The importance of hotel attributes in contributing to travelers' satisfaction in the Hong Kong hotel industry. J Qual Assur Hosp Tour 1:65-83

Rezaei J (2015) Best-worst multi-criteria decision-making method. Omega (United Kingdom) 53:49-57

Rhee HT, Yang S-B (2015a) How does hotel attribute importance vary among different travelers? An exploratory case study based on a conjoint analysis. Electron Mark 25:211-226

Rhee HT, Yang SB (2015b) Does hotel attribute importance differ by hotel? Focusing on hotel star-classifications and customers' overall ratings. Comput Human Behav 50:576-587

Rondan-Cataluña FJ, Rosa-Diaz IM (2014) Segmenting hotel clients by pricing variables and value for money. Curr Issues Tour 17:60-71

Saaty TL (1980) The analytic hierarchy process: planning, priority setting, resources allocation. McGraw, New York

Saaty TL (2002) Decision making with the analytic hierarchy process. Sci Iran 9:215-229

Saleh F, Ryan C (1992) Client perceptions of hotels. Tour Manag 13:163-168

Shah C, Trupp A (2020) Trends in consumer behaviour and accommodation choice: perspectives from India. Anatolia 31:244-259

Shanka T, Taylor R (2013) An investigation into the perceived importance of service and facility attributes to hotel satisfaction. Curr Issues Dev Hosp Tour Satisf 4:119-134

Shin H, Kang J (2020) Reducing perceived health risk to attract hotel customers in the COVID-19 pandemic era: Focused on technology innovation for social distancing and cleanliness. Int J Hosp Manag 91:102664

Simon HA (1979) Rational decision making in business organizations. Am Econ Rev 69:493-513

Singh AK (2016) Competitive service quality benchmarking in airline industry using AHP. Benchmarking 23:768-791

Sirakaya E, Woodside AG (2005) Building and testing theories of decision making by travellers. Tour Manag 26:815-832

Sohrabi B, Vanani IR, Tahmasebipur K, Fazli S (2012) An exploratory analysis of hotel selection factors: a comprehensive survey of Tehran hotels. Int J Hosp Manag 31:96-106

Song H, Lin S, Witt SF, Zhang X (2011) Impact of financial/economic crisis on demand for hotel rooms in Hong Kong. Tour Manag 32:172-186

Sparks BA, Browning V (2011) The impact of online reviews on hotel booking intentions and perception of trust. Tour Manag 32:1310-1323

Stangl B, Inversini A, Schegg R et al (2016) Hotels' dependency on online intermediaries and their chosen distribution channels portfolios. Int J Hosp Manag 52:87-96

Statistical Office in Kraków (2017) Tourism in Malopolska voivodeship in 2016. Kraków

Tkaczynski A, Rundle-Thiele S, Beaumont N (2010) Destination segmentation: a recommended two-step approach. J Travel Res 49:139-152

Toh RS, Raven P, DeKay F (2011) Selling rooms: hotels vs. third-party websites. Cornell Hosp Q 52:181-189

Tsaur S-H, Tzeng G-H (1996) Multiattribute decision making analysis for customer preference of tourist hotels. J Travel Tour Mark 4:55-69

Wang L, Wang XK, Peng JJ, Wang JQ (2020) The differences in hotel selection among various types of travellers: a comparative analysis with a useful bounded rationality behavioural decision support model. Tour Manag 76:103961

Wilensky L, Buttle F (1988) A multivariate analysis of hotel benefit bundles and choice trade-offs. Int J Hosp Manag 7:29-41

Wong KKF, Chi-Yung L (2002) Predicting hotel choice decisions and segmenting hotel consumers: a comparative assessment of a recent consumer based approach. J Travel Tour Mark 11:17-33

Xia H, Vu HQ, Lan Q et al (2019) Identifying hotel competitiveness based on hotel feature ratings. J Hosp Mark Manag 28:81-100

Xu X (2018) Does traveler satisfaction differ in various travel group compositions? Evidence from online reviews. Int J Contemp Hosp Manag 30:1663-1685 
Yacouel N, Fleischer A (2012) The role of cybermediaries in reputation building and price premiums in the online hotel market. J Travel Res 51:219-226

Yang Y, Park S, Hu X (2018) Electronic word of mouth and hotel performance: a meta-analysis. Tour Manag 67:248-260

Ye Q, Law R, Gu B (2009) The impact of online user reviews on hotel room sales. Int J Hosp Manag 28:180-182

Ying S, Chan JH, Qi X (2020) Why are Chinese and North American guests satisfied or dissatisfied with hotels? An application of big data analysis. Int J Contemp Hosp Manag 32:3249-3269

Zaman M, Botti L, Thanh TV (2016) Weight of criteria in hotel selection: an empirical illustration based on tripadvisor criteria. Eur J Tour Res 13:132-138

Zeithaml VA (1988) Consumer perceptions of price, quality, and value: a means-end model and synthesis of evidence. J Mark 52:2-22

Zemke DMV, Neal J, Shoemaker S, Kirsch K (2015) Hotel cleanliness: will guests pay for enhanced disinfection? Int J Contemp Hosp Manag 27:690-710

Publisher's Note Springer Nature remains neutral with regard to jurisdictional claims in published maps and institutional affiliations. 